\title{
Caminhos e distâncias: um diálogo entre psicose infantil e educação
}

\author{
Carlos Alberto Severo Garcia Júnior* \\ Maria Inês Naujorks**
}

\section{Resumo}

A produção teórica acerca dos enlaces existentes entre psicose infantil e Educação Especial é recente. Educadores, pais e profissionais da saúde ainda se deparam com significativas dificuldades relacionadas aos processos educacionais inclusivos destas crianças. Pretende-se com este estudo tecer algumas considerações a respeito da contribuição da psicanálise para o desnovelar destes nós, a partir do entendimento da subjetividade das crianças com psicose. O objetivo foi o de percorrer, através dos diversos fios do pensamento psicanalítico, caminhos que possibilitem o diálogo entre as aproximações e os distanciamentos da produção de conhecimento acerca da educação do sujeito/aluno com psicose infantil. Para isso, tramaram-se algumas relações entre estes campos teóricos, a partir de uma pesquisa bibliográfica cujo corpus de análise compreendeu quatro periódicos entre os anos de 1996 e 2008 ligados a área da educação, quais sejam: Revista Brasileira de Educação, Revista Brasileira de Educação Especial, Revista Educação Especial e Revista Estilos da Clínica. Foram identificados 1147 artigos e destes apenas 57 relacionados ao tema, os quais foram utilizados direta ou indiretamente neste estudo. Utilizase como tear a teoria freudo-lacaniana para amarrar e sustentar a discussão construída a partir da seleção de estado da arte. Observou-se que os trabalhos explicitados, de modo geral, falam de um sujeito em estruturação, transbordado por uma subjetivação. A produção a respeito do tema ainda é incipiente, daí a necessidade de mais estudos e publicações. Percebeu-se, por fim, que a contribuição da psicanálise para a educação seria na perspectiva de um trabalho com o que não se fecha, em um tempo de formação, pois olhar para estes sujeitos é vê-los em construção.

Palavras-chave: psicose infantil; educação especial; psicanálise; periódicos.

\footnotetext{
* Psicólogo, Especialista em Educação Especial (UFSM), Mestre em Educação (UFSM) e Residência Integrada em Saúde (GHC), Santa Maria, Rio Grande do Sul, Brasil.

** Doutora em Psicologia (USP). Professora orientadora do Programa de Pós-Graduação em Educação, Universidade Federal de Santa Maria (UFSM), Santa Maria, Rio Grande do Sul, Brasil.
} 


\title{
Ways and distances: a dialogue between childhood psychos and education
}

\begin{abstract}
The theoretical discussion about the links between childhood psychosis and Special Education is recent. Educators, parents and health professionals still face significant difficulties related to the educational processes inclusive of these children. The aim of this study was to make some considerations about the contribution of psychoanalysis to disentangle some these nodes, from the understanding of the subjectivity of children with psychosis. The goal was to go through the various threads of psychoanalytic thinking, ways that allow for dialogue between the approaches and the distancing of production of knowledge about the subject of education / student with childhood psychosis. For this, they plotted a few relationships between these theoretical fields, from a corpus of literature whose analysis included four journals between 1996 and 2008 linked to the education, which are: Revista Brasileira de Educação, Revista Brasileira de Educação Especial, Revista Educação Especial e Revista Estilos da Clínica. We identified 1147 articles, of which only 57 related to the topic, which were directly or indirectly used in this study. It is used as loom freudian-lacanian theory to tie and hold a discussion built upon the selection of state of the art. It was observed that the work explained, in general, speak of a subject in structuring, overwhelmed by a subjectivity. The production on the subject is still incipient, hence the need for more studies and publications. It was noticed, finally, that the contribution of psychoanalysis to education would be the prospect of working with what is not closed, in a time of formation, as look at these children is to see them under construction.
\end{abstract}

Keywords: childhood psychosis; special education; psychoanalysis; periodicals.

\section{Introdução}

O presente artigo pretende percorrer e desnovelar diversos fios do pensamento psicanalítico, para interrogar, tecer e construir um diálogo entre as possíveis aproximações e distanciamentos sobre a produção de conhecimento acerca da educação do sujeito/aluno com psicose infantil. O desafio é pensar os múltiplos lugares educacionais, pedagógicos, escolares (im)possíveis tecidos a partir de diferentes fios-sentidos, interrogando Quem são esses sujeitos?

Este estudo, portanto, trata-se de uma pesquisa teórica e aborda a produção científica publicada em periódicos qualificados nas áreas da educação e psicologia. De tal modo, são analisados os artigos de referencial teórico-psicanalítico freudo-lacaniano em quatro periódicos com publicação entre 1996 e 2008 que tratam do tema psicose infantil e educação. Para tanto, foram selecionados os periódicos: Revista Brasileira de Educação, Revista Brasileira de Educação Especial, Revista Educação Especial e Revista Estilos da Clínica. Sendo assim, procura-se tecer uma malha que possa contemplar a existência 
ou ausência de um tecido entramado para as possibilidades educacionais e subjetivas de crianças com psicose.

\section{Educação e Educação Especial: tecendo fios}

Os aspectos históricos da educação e das políticas educacionais brasileiras evidenciam um atraso quando comparados aos países europeus, em relação aos processos de escolarização e à construção dos parâmetros legais e das políticas públicas, sobretudo, para pessoas com necessidades especiais. Tal atraso decorre de uma estrutura social patriarcal e pelo histórico de colonialismo (VICTOR, 2009).

Tradicionalmente a Educação Especial organizou-se como atendimento educacional especializado substitutivo ao ensino comum. Houve no Brasil a criação de diversas instituições especializadas, escolas especiais e classes especiais, mesmo evidenciando diferentes compreensões, terminologias e modalidades. A expansão destas instituições deu-se pela interferência do caráter filantrópico de famílias nas quais havia membros com deficiência (BRASIL, 2008).

O surgimento de instituições não necessariamente especializadas, destinadas a pessoas com deficiências, tendo em perspectiva atendimentos assistenciais que se baseavam num enfoque médico-clínico, interferiam no educacional, como afirma Mazzotta (2005, p. 15),

[...] é frequente a referência a situações de atendimentos a pessoas deficientes (crianças e/ou adultos) como sendo educacionais, quando uma análise mais cuidadosa revela tratar-se de situações organizadas com propósitos que não o educacional.

Desse modo, a interferência do saber médico na investigação e na tentativa de "revelar" quem são esses sujeitos deixa marcas e repercute na educação. É nesse sentido que, originalmente, a constituição da Educação Especial como campo de saber e área de atuação se dá a partir de um modelo médico ou clínico, afirmam Glat e Fernandes (2005).

Estes sujeitos, portanto, com a Constituição Federal de 1988, recebem um novo lugar, isto é, são incluídos no espaço da cidadania e instituídos em um discurso legislatório, agora incorporado com outra indumentária. Com a promulgação da Constituição de 1988 iniciam-se os debates e discussões a respeito da elaboração de uma nova lei de diretrizes para a educação, a qual é oficializada somente anos depois.

Outro marco fundamental no âmbito da educação foi a Declaração de Salamanca, em 1994, realizada na Conferência Mundial de Educação Especial, na Espanha, e versou sobre os princípios, políticas e práticas na área das ne- 
cessidades educativas especiais. Através deste documento internacional se reconhece e marca a necessidade de uma educação inclusiva que respeite a diferença.

Com base nesses marcos históricos, a Lei de Diretrizes e Bases da Educação Nacional (LDB), número 9.394 de 1996, em suas disposições garante a oferta de educação escolar para "educandos portadores de necessidades". Indica uma abordagem para a educação daqueles sujeitos com suas necessidades educacionais e serve de marco referencial para os arranjos da Educação Especial.

Ainda na época da elaboração do documento, o termo portador ainda era utilizado. Atualmente, sabe-se que tanto o verbo "portar" como o substantivo ou o adjetivo "portadora" não se aplicam a uma condição inata ou adquirida que faz parte da pessoa. Por exemplo, não dizemos e nem escrevemos que certa pessoa é portadora de olhos verdes ou pele morena.

Baptista (2002, p. 162-163) afirma o seguinte:

educação inclusiva é um movimento e um paradigma. Um movimento, porque podem ser reconhecidas ações que se transformam e que propõem novas transformações. Tais ações associam-se a práticas diferentes e diferenciadas, as quais rompem com verdades estabelecidas e determinam a falência de critérios de classificação que resistiram durante décadas. Um paradigma, porque lança uma perspectiva que tem propostas que imprimem uma direção ao trabalho educativo e à reflexão em educação.

A política de educação brasileira, considerando os pressupostos da Declaração de Salamanca, a partir da LDB 9.394/96, oferece subsídios que sustentam o conceito de educação inclusiva, no qual a ênfase se dá sobre as respostas educativas dos alunos na escola. Entretanto, os três artigos que compõem a LDB não contemplam a complexidade das discussões acerca do objetivo da Educação Especial na educação inclusiva.

Dessa forma, a partir de 2008, a Secretaria de Educação Especial (SEESP) desenvolve programas, projetos e ações a fim de implementar a Política Nacional de Educação Especial na Perspectiva da Educação Inclusiva. Este documento configura definições importantes para este campo, estabelecendo a Educação Especial como uma modalidade que deveria perpassar todos os níveis de ensino, reforçando a construção da transversalidade da Educação Infantil até a Educação Superior.

Os preceitos desta política demarcam, por exemplo, como público-alvo da Educação Especial os alunos com deficiência, transtornos globais do desenvolvimento e com altas habilidades. Assim, as crianças com psicose ganharam 
"borda-sentido" no campo da educação e Educação Especial. Anteriormente eram pacientes, agora passaram a ser considerados alunos. Além disso, vem propor a garantia do atendimento educacional especializado, com a formação de professores e demais profissionais da educação para a inclusão escolar (BRASIL, 2008).

A inclusão escolar traz em sua defesa ora a igualdade de todas as crianças, ora a sua diferença e coloca a professora em sala de aula numa posição que traz dificuldades para escolhas. Em determinadas circunstâncias, as regras são iguais para todas, tornando inviável a presença daquela criança que somente se balança ritmicamente. Ao passo que, em outras situações, devem ser respeitadas as diferenças, permitindo que Joãozinho rasgue todos os desenhos, afirma Kupfer (2005).

Mas como propor tais movimentos nos educadores e demais atores envolvidos com a educação? De que forma precipitar essas mudanças? E quais as produções de conhecimento no campo da Educação Especial orientada pela psicanálise freudo-lacaniana? São questões provocadoras e que instigam um caminho.

\section{Caminhos de uma investigação: um processo, uma trama}

O presente estudo trata-se de uma pesquisa bibliográfica no campo da educação cujo percurso se deu através de uma investigação da produção textual, bibliográfica e documental - estética do corpus $^{1}$ - acerca da psicose na infância. Nesse sentido, o material interrogado, objeto de pesquisa e discussão desse estudo, são os artigos apresentados em quatro revistas de educação e psicologia com circulação nacional relacionadas à construção de conhecimentos "interdisciplinares" na área da educação.

A seleção dos quatro periódicos científicos na área da educação foi estabelecida pela importância, representatividade e reconhecimento destas produções científicas desenvolvidas no país, além de ser valorizada também a avaliação da Coordenação de Aperfeiçoamento de Pessoal de Nível Superior (CAPES) do Qualis (2007-2009), um conjunto de procedimentos para estratificação da qualidade da produção intelectual dos programas de pós-graduação dos periódicos.

Especificamente, verso do seguinte corpus analítico:

1) Revista Brasileira de Educação Especial, apresentada pela primeira vez em 1992. Periódico responsável pela transmissão de pesquisas e estudos sobre a Educação Especial e áreas afins no Brasil. Qualis A2.

2) Revista Educação Especial, registrada inicialmente em 1987 com o nome de Cadernos de Educação Especial; a partir de 2000 passou a chamarse pelo nome atual. Qualis B2. 
3) Revista Brasileira de Educação, publicada pela primeira vez em 1995, trazendo a discussão da Associação Nacional de Pós-Graduação e Pesquisa em Educação (ANPEd). Qualis A1.

4) Revista Estilos da Clínica, periódico do Instituto de Psicologia da Universidade de São Paulo (USP) em colaboração com o Laboratório de Estudos e Pesquisas Psicanalíticas e Educacionais sobre a Infância (IP/FEUSP) com sua primeira publicação em 1996. Qualis B1.

Optou-se, por ser emblemática na história da educação, utilizar a Lei de Diretrizes e Bases da Educação, de 1996, como fio inaugural para bordar, criar figuras ou ornatos com os tecidos de diferentes tipos. O "recorte" cronológico deste estudo se trata de uma demarcação com caráter homogeneizante, com o intuito de aproximar as relações entre o corpus analítico e, de certa forma, eliminar a discrepância temporal entre os artigos.

O primeiro "ponto" constitui-se através da leitura dos títulos e palavraschave que identificavam a utilização de terminologias referendadas pelos diferentes campos teóricos que abordam o tema da psicose infantil e as possíveis relações com a educação em todos os artigos das quatro revistas de 1996 a 2008. Foram consideradas para análise somente artigos classificados como relato de pesquisa, ensaio, dossiê, revisão bibliográfica, relato de experiência, experiência institucional, espaço aberto ou depoimento. Foram desconsideradas para análise as resenhas.

Especificamente, nos títulos e palavras-chave foram consideradas as seguintes nomenclaturas: Transtornos Globais do Desenvolvimento (TGD) Distúrbios Globais do Desenvolvimento (DGD) Transtornos Invasivos do Desenvolvimento (TID) e Autismo, uma vez que são terminologias utilizadas com frequência através de sistemas classificatórios em âmbito nacional e que, a partir do referencial teórico norteador neste estudo, contemplam a psicose infantil.

Posteriormente à leitura dos títulos e palavras-chave, o segundo ponto constitui-se da contagem daqueles que contemplavam os elementos definidos no primeiro ponto. Seguiu-se a leitura dos resumos para então pré-selecionar aqueles cujos conteúdos estavam relacionados com o tema da pesquisa.

A saber: Revista Brasileira de Educação, com um total de 373 artigos publicados, sendo apenas um artigo pré-selecionado com possível relação ao tema; Revista Estilos da Clínica com 310 artigos publicados e 50 artigos préselecionados; Revista Brasileira de Educação Especial com um total de 205 artigos publicados, sendo pré-selecionados três artigos; e, finalmente, Revista de Educação Especial, com 259 artigos na sua soma, sendo pré-selecionados três artigos. Assim, no total de 1147 artigos, apenas 57 foram relacionados diretamente com o tema. 
No terceiro e último "ponto", foi estabelecida a leitura na íntegra dos textos pré-selecionados, a partir dos quais foram tecidos alguns pontos de leitura, isto é, um (entre) laço capaz de vincular, relacionar e conectar os "sujeitos/objetos" de pesquisa que se repetem, se encontram e se afastam nos trabalhos através dos conceitos psicanalíticos discutidos.

\section{A quimera diagnóstica dos sujeitos com psicose infantil}

No campo da psicopatologia infantil, algumas crianças apresentam graves transtornos em seu desenvolvimento e recebem lugares especiais, compondo uma categoria nosográfica e divulgadas em compêndios e classificações. Existem "instrumentos classificatórios" como, por exemplo, o Manual de Diagnóstico e Estatístico de Distúrbios Mentais, da Associação Americana de Psiquiatria (2002), o DSM-IV-TR, que categoriza as crianças com graves transtornos de desenvolvimento dentro de "distúrbios globais do desenvolvimento", bem como a Classificação Internacional das Doenças, o CID-10 (1993), proposto pela Organização das Nações Unidas (ONU), que inclui estas crianças no grupo dos "transtornos globais do desenvolvimento", terminologia adotada pelo Ministério da Educação. Embora essas convenções resolvam alguns problemas, promovem outros tantos, principalmente relacionados a uma "disputa diagnóstica".

Vasques (2008b, 2009) diz que ambas as obras atendem a uma listagem de sintomas que servem de orientação para um diagnóstico, com o propósito de categorizar. Desse modo, o diagnóstico assume um caráter classificatório, desconsiderando a perspectiva de lugar de sujeito, com o foco muitas vezes voltado para os sintomas e deslocando a atenção das possíveis demandas subjetivas.

Dentro do referencial psicanalítico, por outro lado, alguns autores realizaram estudos sobre a rubrica da psicose infantil como, por exemplo, Melanie Klein, Frances Tustin e, com o referencial de Jacques Lacan, Maud Mannoni, Françoise Dolto e Robert Lefort. Entretanto, a riqueza de trabalhos não estabelece uma definição precisa do que seria verdadeiramente uma psicose infantil (KUPFER, 2007).

Há diferença considerável entre a nosografia psicanalítica e psiquiátrica, tendo esta a noção de incluir e aquela excluir, refere Voltolini (2004). Enquanto o discurso psiquiátrico aborda categorias a partir de definições do que é ou não normal, entendendo a normalidade como homogeneidade, para a psicanálise os conjuntos nosográficos são extensivos a todos. De tal forma, uma nosografia do tipo inclusiva proporciona uma resistência à sustentação de uma prática, que tenha em vista um modelo com a ideia de cura.

Com relação à psicose infantil, Kupfer (2000) aponta que nos estudos sobre o tema também se encontram alguns entraves na leitura do diagnóstico. Existem sérias dificuldades em estabelecer trocas científicas, pois há uma falta 
de concordância entre pesquisadores e profissionais e estudos epidemiológicos, uma vez que o seu objeto de pesquisa não é o mesmo. Neurologistas, psiquiatras, psicólogos e educadores nem sempre falam a mesma língua. Apesar da significativa produção, ainda não há uma definição precisa dessas patologias com suas diferentes manifestações e, portanto, um consenso sobre o que sejam as psicoses na infância.

A mesma autora traz uma reflexão importante sobre a corrente biológica e a psicanalítica. É necessário salientar a inegável contribuição do conhecimento das bases neurológicas, no entanto, a criança, se reduzida ao biológico, jamais sairá desta condição caso não opere outro que lhe conduza ao mundo. Um outro que lhe ensaie os atos para além dos reflexos e, principalmente, que Ihe possa ofertar um sentido para que, desse modo, seja introduzida no mundo da linguagem.

Cabe salientar que a psicose na criança não se revela da mesma forma que no adulto. Na infância e adolescência os sujeitos ainda estão em constituição, ou seja, a diferença é o tempo, diz Calligaris (1989). O tempo seria um fator diferencial, pois caso ocorra uma crise psicótica em idade precoce, há uma interrupção brusca da estruturação e obstrui, ao mesmo tempo, o desenvolvimento.

Nesse sentido, Jerusalinsky (1993) propõe que as psicoses infantis devem ser consideradas como não decididas, "[...] porque ainda está para se decidir até que ponto esta inscrição poderia vir a adquirir uma formulação metafórica" (p. 63-64), uma vez que "[...] é possível que um significante qualquer na infância venha a adquirir uma força que lhe dê uma capacidade substitutiva da inscrição original". O autor considera que é na adolescência o período em que há uma "soldagem" entre o simbólico do significante e o ato sexual.

Portanto, na psicanálise freudo-lacaniana, as psicoses na infância são designadas como estruturas não-decididas, isto é, não organizadas como estrutura, conforme estabelece Bernardino (2007) que acredita se tratar de um conceito decorrente de duas noções.

Primeiramente, por questões teóricas, o inconsciente estruturado pela linguagem outorga o acesso à significação no só-depois. "A infância é o tempo das inscrições e da confirmação dessas inscrições, vindas do Outro" (BERNARDINO, 2007, p. 61). Neste "tempo gerúndio" como chama a autora, à inscrição significante Nome-do-Pai, posição da falta estrutural do campo simbólico, necessita de tempos para se inscrever e operar, sendo que "[...] obedecem a uma lógica psíquica, de ressignificação do depois sobre o antes, tal como Lacan descreveu" (BERNARDINO, 2007, p. 62).

Em segundo lugar, por razões clínicas, pois afirma Bernardino (2007) que fechar um diagnóstico de psicose na infância contraria o estado de inacabamento que é característico da infância e, de tal modo, atrapalha o 
surgimento do sujeito, isto é, "passa-se a reforçar as defesas psicóticas em detrimento de abrir outras possibilidades para o sujeito de se posicionar perante o Outro" (2007, p. 64).

Por isso, é necessário olhar para as psicoses infantis na/da constituição subjetiva como impasses, uma vez que são estruturas em processo de construção. Dessa forma,

acentua-se o caráter mutável dessa maneira, não de ser, mas de estar na infância, o que pode abrir espaço para a construção de alternativas existenciais. Trata-se, assim, de uma provisoriedade onde o tempo (psíquico e cronológico) apresenta-se como um diferencial. (VASQUES, 2008a, p. 18)

Calligaris (1989, p. 27) aponta que na psicose infantil "a situação não está decidida, o que não quer dizer que o prognóstico seja necessariamente melhor ou otimista". A dimensão temporal da foraclusão faria alusão a uma série de tempos diferentes. Apesar de estar no Outro desde o começo, espera-se uma confirmação.

O tema das psicoses infantis percorre um longo processo históricocultural de atenção à infância e à psicopatologia infantil. A construção dessa historicidade referenda um amplo espectro de denominações e classificações tais como: deficientes, desvalidos, idiotas, anormais, loucos, dementes etc. (VASQUES, 2008a).

O próprio processo de compreensão sobre a conceituação das psicoses infantis, nos campos da saúde e da educação, está mesclado sobre a história dos atendimentos sobre este grupo, como nos aponta Vasques (2008a). Nesta direção, os apontamentos da educação, Educação Especial e inclusiva são tentativas de arquitetar novas formas de ler, valorizar e reconhecer a diversidade humana.

No campo da educação, o primeiro relato de uma experiência marcante acompanhada e desenvolvida por Jean Itard (1774-1838), O Selvagem do Aveyron, ocorre com um menino de onze ou doze anos encontrado na França. Em seu relatório, Itard (2000) aponta algumas características, como movimentos espasmódicos e muitas vezes convulsivos, balanço contínuo do corpo, hábito de morder e arranhar quando contrariado, "nenhuma espécie de afeição àqueles que o serviam; enfim, indiferente a tudo e não dando atenção a nada" (p. 130).

Ao evidenciar o caso de Victor, o médico-pedagogo Itard propõe uma reflexão importante acerca do diagnóstico do menino. A proposta diagnóstica de "idiota" atribuída por Philippe Pinel (1745-1826), psiquiatra francês, é contestada. De acordo com Itard, "Victor seria possuidor de uma deficiência, porém pensava que essa pudesse estar relacionada com o seu modo de vida prece- 
dente [...]" (BAPTISTA; OLIVEIRA, 2002b, p. 100), ou seja, a falta de contato com outros seres humanos teria Ihe deixado em uma "privação social".

O argumento utilizado por Itard para sustentar que as dificuldades de Victor iriam além de aspectos orgânicos, pela ausência de contato social, destoava do discurso hegemônico de sua época. Apontar o homem como algo em construção e inacabado é uma proposta ousada. Se para Pinel o menino foi abandonado por seus pais por o terem considerado um retardado, em contrapartida, Itard sustenta a opinião de que Victor era retardado - psicótico porque foi abandonado. Portanto, "pouco a pouco, há um trabalho de enquistamento da psicose, a partir de um processo de recalcamento que se apoia em um processo de aprendizagem e progride com os ensaios e erros" (BERGÈS; BALBO, 2003, p. 30).

Paulatinamente, as crianças, nos seus ensaios pela descoberta do mundo, no encontro com as palavras e com os objetos, constroem redes metafóricas. Metáforas no brincar e no representar que revelam algo que não estava onde antes era uma palavra enunciada de forma metonímica (MEIRA, 2003).

Há, nesse sentido, um retorno à experiência de Itard, motivado pelo reencontro dos fundamentos da educação e da clínica. Cria-se uma forma de pautar uma crítica à pedagogia e terapia mais positivista, isto é, uma reeducação e adaptação que mesmo hoje não inclui o sujeito, de tal modo que, depois de duzentos anos, conforme Vasques (2008), os mesmos dilemas em relação às possibilidades para a escolarização das crianças com psicose infantil ainda trazem indagações.

\section{(H)À possibilidade de um contorno: costurando o tecido}

Constatou-se a escassa produção sobre o tema estudado nas revistas dedicadas ao campo da educação, o que de sobremaneira surpreende, tendo em vista seus portes institucionais.

Acerca da estrutura dos artigos consultados, pode-se notar que, em alguns deles, o titulo e o resumo não contemplavam de forma clara os temas abordados, enquanto noutros nem sequer existia resumo. Esses achados falam da qualidade da produção teórica, a qual vem sendo avaliada de maneira mais criteriosa, principalmente após o advento da indexação destas publicações, o que pôde ser verificado nos artigos mais recentes, todos os quais apresentavam título e resumo adequados ao assunto pretendido. o tema.

Alguns dos artigos pesquisados merecem destaque pelo encontro com

Kupfer e Petri (2000) discutem a inclusão de crianças psicóticas e autistas partindo da tese de que essa inclusão é terapêutica. Nesse sentido, as 
autoras propõem examinar o que muitos professores costumam perguntar: "Por que ensinar a quem não aprende?".

Antes de adentrar nessa questão, as autoras situam quem são as crianças especiais que se supõe que devam ser incluídas. Formula-se a ideia de que as crianças especiais existem por causa de diferenças "naturais" e que estão fora das escolas porque há um preconceito social. Assim, criam-se leis inclusivas que obrigam o tecido social a reincorporar para dentro de seus muros escolares o que havia sido expelido.

Entretanto, "[...] a criança especial é uma criação produzida no e pelo discurso social escolar posto pela circulação no início da modernidade" (KUPFER; PETRI, 2000, p. 110). Na produção de um discurso pode-se produzir um objeto que não se encontrava ali antes. Quando se instala a escola, a criança especial acompanha esse movimento. Desse modo, cria-se uma nova categoria antes inexistente e daí a necessidade de nomeação.

Lacan (1987, p. 215) clareia a ideia:

O poder de nomear os objetos estrutura a própria percepção...é pela nomeação que o homem faz subsistir os objetos numa certa consistência. Se estivessem apenas numa relação narcísica com o sujeito, os objetos não seriam nunca percebidos de maneira instantânea. A palavra, a palavra que nomeia, é o idêntico... O nome é o tempo do objeto. A nominação constitui um pacto, pelo qual dois sujeitos no mesmo tempo concordam em reconhecer o mesmo objeto... se os sujeitos não se entenderam sobre este reconhecimento, não haverá mundo algum, nem mesmo perceptivo, que se possa manter por mais de um instante.

De acordo com Rickes (2007), a materialização na linguagem mostra o caminho aberto no qual o sujeito está convocado a construir respostas para os diversos impasses de seu tempo e de sua vida, num mundo em que os argumentos estão vetorizados por um porvir. Ao nomear é possível ganhar permanência e consistência, porém, um nome só é assegurado por um acordo, um contrato, um entendimento entre as partes que operam a nomeação. Portanto:

Toda nomeação, assim como tudo que reconhecemos como participando da seara humana, só se consuma quando encontra o endereço de uma escuta que a reconhece como legítima no sistema simbólico compartiIhado pelos habitantes de uma organização social. (RICKES, 2007, p. 21)

Historicamente, percebe-se uma tendência da educação em objetalizar a criança. Na contracorrente, já na década de 60, na França, Mannoni (1977) 
começou a questionar algumas posturas e discursos oficiais dos centros médico-pedagógicos que reforçavam este lugar de objeto da criança com transtornos de desenvolvimento. Assim, a partir destes questionamentos, em conjunto com alguns colegas, fundou a Escola Experimental de Bonneuil-sur-Marne, importante espaço para atendimento a crianças psicóticas e autistas. Mannoni explora, a partir da psicanálise, o campo da Educação Especial ao colocar em xeque algumas noções acerca da educação em geral, da psiquiatria e dos serviços de saúde mental, apontando a ausência de lugar para sujeitos em dispositivos que foram criados justamente para atendê-los.

A proposta de conexão entre educação e terapêutica, discutida por Pechberty (2007), traz a ideia da educação por vir, na escola, para a criança psicótica. A partir desta abertura, a entrada no laço escolar pode ser diligente, terapêutica, humanizante e identificadora. De tal modo, na dimensão educativa, a escola é a afirmação de regras e de interditos para se viver com os outros e que, no caso de crianças psicóticas, autistas ou transbordadas pelas excitações pulsionais, são valiosas.

Sustenta-se a possibilidade de aproximação entre psicanálise e educação, nomeada por Educação Terapêutica. Kupfer (1997) apresenta este casamento como um conjunto de práticas que conciliam educação e tratamento para crianças cuja inscrição no registro simbólico apresenta falhas a ponto de comprometer a sua constituição subjetiva. Em outros termos, uma intervenção que instale um lugar social, que opere nas relações estruturais da criança, articulando conhecimento, sujeito, significante e palavra.

Dessa forma, a perspectiva da Educação Terapêutica é a de traçar caminhos não lineares, auxiliar no enfrentamento entre encontros e desencontros dos sujeitos com seus limites, alcances e entrepostos educacionais e subjetivos e, ainda, inscrever um modo de fazer intervenção, interferência e interposição com o que não cessa de interrogar.

A Educação Terapêutica visa - estando o verbo empregado em três sentidos: o que dá visto, o que vê e o que almeja - o sujeito. Isto é, um modo de operar que atenta para a retomada da estruturação psíquica interrompida. Como refere Kupfer, Oliveira e Guglielmetti (1998, p. 16), "a Educação Terapêutica é refazer o elo entre, de um lado, o sujeito autorreferido, delirante, e, de outro, o discurso social - ou seja, a instituição tomada em sua vertente simbólica".

Conforme Milmann (2003, p. 48): "Se a educação tem uma função para a psicose na infância, também a psicose tem isso a transmitir aos educadores". Um sujeito fala desde um lugar no discurso e na psicose não há transparência da linguagem. Assim, situar a singularidade da criança com psicose abordada pelo saber da psicanálise é um atravessamento possível para a escola que pretende incluí-la. 
Assim, inventar um lugar de trânsito, de leitura que possibilite seguir adiante é criar condições para o possível. Como contar, tecer, imaginar um conjunto de fatos e situações que constituem uma narrativa, uma história, uma série de acontecimentos mais ou menos desencadeados, reais ou imaginários, por meio de palavras ou de imagens. Mesmo que o enredo de uma história possa parecer uma completa ficção. Nesse sentido, a produção de significados nem sempre se encontra totalmente definida, estabelecida e escrita, mas em um efeito fundado na experiência (a posteriori), num tempo retroativo - próximos ao fim, lembramos do começo.

\section{Trama final}

A psicose não-decidida conserva o potencial da transformação. Num trabalho/olhar/escuta para um sujeito de desejo pode desfazer-se um equívoco. É misturar termos estrangeiros, coisas estranhas e mesclar com uma linguagem imprópria, mas que propõe uma própria. "A psicose é um pensamento do avesso", ${ }^{2}$ pois aponta a impossibilidade do sujeito representar-se de modo contínuo no discurso. Por isso, a importância de construir com o sujeito a possibilidade de sustentar escolhas que faz em suas relações com os outros (laço social).

A contribuição da psicanálise para a educação inclusiva é apontar o momento da entrada da criança na escola como um registro de uma singularidade e, ao mesmo tempo, marcar o encontro na classe em que irá estudar juntamente com colegas que poderão servir de referência identificatória. Meira (2006) diz que é um pedido desorganizador para a criança constituir laços apenas com crianças que the espelhem a imagem do que não são.

A inclusão é um direito, sem dúvida. Entretanto, antes de ser uma imposição "legal" há outras imposições que necessitam de espaço de reflexão. Como, por exemplo, atender a demanda heterogênea que este grupo de crianças pode suscitar na escola? Como garantir a potencialidade de uma intervenção? E como podemos encarar as dificuldades que temos, respeitando as diferenças? Missão difícil. Questões que induzem a necessidade de instituições que se ordenem pela interdisciplinaridade.

Enfim, o acúmulo teórico sob o discurso da Educação Especial no que diz respeito ao tema da psicose infantil ainda é incipiente e revela que ainda temos que encontrar "focos de luz" que auxiliem no tramar dos muitos fios. Temos muito o que aprender, acumular e produzir sobre/com a psicose infantil, daí a necessidade de mais estudos e publicações.

\section{Referências}

BAPTISTA, C. R. Educação Inclusiva (entrevista). Ponto de vista: Revista de Educação e Processos Inclusivos (UFSC), n. 3/4, p. 161-172, 2002. 
BAPTISTA, C. R.. OLIVEIRA, A. C. Lobos e médicos: primordios na educação dos "diferentes". In: BAPTISTA, C. R.; BOSA, C. (Orgs.). Autismo e Educação: reflexões e propostas de intervenção. Porto Alegre: Artmed, 2002b, p. 93-109.

BATISTA, C. A. M.; MANTOAN, M. T. E. Atendimento educacional especializado em deficiência mental. In: GOMES, A. L. L. et al. Atendimento educacional especializado: deficiência mental. Brasília: MEC, SEESP, p. 13-44, 2007.

BERGÈS, J; BALBO, G. Há um infantil da psicose? Porto Alegre: CMC, 2003.

BERNARDINO, L. M. F. As psicoses não-decididas da infância: um estudo psicanalítico. São Paulo: Casa do Psicólogo, 2004.

. A intervenção psicanalítica nas psicoses não-decididas da infância. In: Comissão de Aperiódicos da Associação Psicanalítica de Porto Alegre (APPOA). Psicose: abertura da clínica. Porto Alegre: Libretos, p. 54-66, 2007.

BRASIL. Constituição da República Federativa do Brasil. Brasília: Imprensa Oficial, 1988.

Declaração de Salamanca e Linha de Ação sobre Necessidades Educativas Especiais. Brasília: CORDE, 1994.

Lei de Diretrizes e Bases da Educação Nacional. Ministério da Educação. LDB 9.394, de 20 de dezembro de 1996.

. Política Nacional de Educação Especial na Perspectiva da Educação Inclusiva. Secretaria de Educação Especial/MEC. Inclusão: Revista da Educação Especial. Edição Especial. v. 4, n.1, jan./jun., p. 7-17, 2008.

CALLIGARIS, C. Introdução a uma clínica diferencial das psicoses. Porto Alegre: Artes Médicas, 1989.

GLAT, R; FERNANDES, E.M. Da Educação Segregada à Educação Inclusiva: uma Breve Reflexão sobre os Paradigmas Educacionais no Contexto da Educação Especial Brasileira. Inclusão: Revista da Educação Especial. Brasília, p. 35-39, out. 2005.

ITARD, J. Relatório I: Da educação de um homem selvagem ou dos primeiros desenvolvimentos físicos e morais do jovem Selvagem do Aveyron. In: BANKSLEITE, L.; GALVÃO, I. (Org.). A educação de um selvagem: as experiências pedagógicas de Jean Itard. São Paulo: Cortez, p. 123-177, 2000 (Original de 1801).

JERUSALINSKY, A. Psicose e Autismo na Infância: uma questão de linguagem. Boletim, APPOA, n. 9, p. 62-73, nov. 1993.

KUPFER, M.C.M. Educação terapêutica: o que a psicanálise deve pedir à educação. Estilos da Clínica, $1^{\circ}$ Semestre, ano 1, n. 2, p. 53-61, 1997. 
. Notas sobre o diagnóstico diferencial da psicose e do autismo na infância. Psicol. USP, São Paulo, v. 11, n. 1, p. 85-105, 2000.

. Inclusão escolar: a igualdade e a diferença vista pela psicanálise. In: COLLI, F.A.G. (org.) Travessias inclusão escolar: a experiência do grupo ponte Pré-escola Terapêutica Lugar de Vida. São Paulo: Casa do Psicólogo, 2005. p.17-27.

Escuta, 2007.

Educação para o Futuro: Psicanálise e Educação. 3 ed. São Paulo:

KUPFER; M.C.M., OLIVEIRA; L.G.M, GUGLIELMETTI; M.L. Lugar de Vida: 10 anos depois. Estilos da Clínica, ano 3, n. 5, p. 10-18, 1998.

KUPFER, M.C.M.; PETRI, R. "Por que ensinar a quem não aprende?" Estilos da Clínica, $1^{\circ}$ semestre, ano 5, n. 9, p. 109-117, 2000.

LACAN, J. Seminário Livro 2: O eu na teoria de Freud e na técnica da Psicanálise. Rio de Janeiro: Jorge Zahar, 1987. (Original de 1954-1955)

MANNONI, M. Educação Impossível. Rio de Janeiro: Francisco Alves, 1977.

MAZZOTTA, M. J. S. Educação Especial no Brasil: História e políticas públicas. 5 ed. São Paulo: Cortez, 2005.

MEIRA, A. M. G. Sobre a infância, as psicoses e a escola na contemporaneidade. Correio da APPOA, Porto Alegre, n. 114, p. 21-30, jun. 2003.

. Contribuições da psicanálise para a educação inclusiva. Escritos da Criança, Porto Alegre, Centro Lydia Coriat, n. 6, 2. ed., p. 41-52, 2006.

MILMANN, E. A instância da letra na leitura. Estilo da Clínica, $1^{\circ}$ semestre, ano 8, n. 14, p. 30-49, 2003.

PECHBERTY, B. O debate entre o cuidado e a educação: práticas clínicas atuais. Estilos da Clínica, $1^{\circ}$ semestre, ano 12, n. 22, p.14-25, 2007.

RICKES, S.M. Entre a sujeição e o domínio, vibra a posição sujeito: Reverberações éticas de uma concepção do sujeito como lugar enunciativo. Psicologia \& sociedade, v. 19, n. 2, p. 15-24, 2007.

VASQUES, C. K. Alice na Biblioteca Mágica: Uma Leitura Sobre o Diagnóstico e a Escolarização de Crianças com Autismo e Psicose Infantil. Tese (Doutorado) - Universidade Federal do Rio Grande do Sul, Faculdade de Educação, Programa de Pós-Graduação em Educação, Porto Alegre, Brasil, Rio Grande do Sul, 2008a.

. Transtornos globais do desenvolvimento e educação: análise da produção científico-acadêmica. In: Reunião Anual da Associação Nacional de Pós-Graduação e Pesquisa em Educação (ANPED), 2008, Caxambú. Anais da $31^{a}$ Reunião Anual da Associação Nacional de Pós-Graduação e Pesquisa 
em Educação (ANPED), p.1-16, 2008b. Disponível em: <http://www.anped.org.br/ reunioes/31ra/1trabalho/GT15-4469—Int.pdf>. Acesso em: jun. 2009.

. Construções em torno de um vazio: uma leitura sobre o diagóstico e seus "modos de usar" na escolarização de sujeitos com autismo e psicose infantil. In: BAPTISTA, C. R.; JESUS, D.M. (Orgs.). Conhecimento e margens: ação pedagógica e pesquisa em educação especial. Porto Alegre: Mediação/CDV/FACITEC, p. 11-26, 2009.

VICTOR; S.L. Sobre inclusão, formação de professores e alunos com necessidades educacionais especiais no contexto da educação infantil. In: BAPTISTA, C. R.; JESUS, D.M. (Orgs.). Conhecimento e margens: ação pedagógica e pesquisa em educação especial. Porto Alegre: Mediação/CDV/FACITEC, p. 107$121,2009$.

VOLTOLINI, R. A desrazão na infância: o discurso analítico e a inclusão. In: Anais do IV Colóquio do LESPI, São Paulo, p.165-171, 2004.

\begin{abstract}
Notas
${ }_{1}$ Proponho esta terminologia para tratar da dimensão plástica e mensurável de um conjunto enunciado e constitutivo, uma maneira particular de representar uma imagem. Pela rubrica da filosofia, uma visão da imagem, isto é, percepção interior da própria imagem interior, uma escopia. Houaiss (2007), gramática skopiá,âs "local de observação", mas com o conteúdo semântico genérico de -scopia, ver (o conceito foi haurido em J. Lacan).

${ }^{2}$ Fala proferida por Alfredo Jerusalinsky em 17 de setembro de 2009, na cidade de Porto AlegreRS, no grupo de estudos "Cartelão" da Associação Psicanalítica de Porto Alegre (APPOA).
\end{abstract}

\title{
Correspondências
}

Carlos Alberto Severo Garcia Júnior - Rua Henrique Dias 140, apt. 201, CEP 97010-220 Santa Maria-RS.

E-mail: cgarciapsi@hotmail.com - minau@uol.com.br

Recebido em 11 de dezembro de 2010

Aprovado em 03 de fevereiro de 2011 